\title{
The effect of temperature and substrate quality on the carbon use efficiency of saprotrophic decomposition
}

\author{
Mats G. Öquist • Björn Erhagen • Mahsa Haei - Tobias Sparrman • \\ Ulrik Ilstedt • Jürgen Schleucher • Mats B. Nilsson
}

Received: 9 June 2016 / Accepted: 6 November 2016 / Published online: 26 November 2016

(C) The Author(s) 2016. This article is published with open access at Springerlink.com

\begin{abstract}
Background and aims Mineralization of soil organic matter (SOM) constitutes a major carbon flux to the atmosphere. The carbon use efficiency (CUE) of the saprotrophic microorganisms mineralizing SOM is integral for soil carbon dynamics. Here we investigate how the CUE is affected by temperature, metabolic conditions, and the molecular complexity of the substrate.

Methods We incubated O-horizon soil samples (with either ${ }^{13} \mathrm{C}$-glucose or ${ }^{13} \mathrm{C}$-cellulose) from a boreal coniferous forest at $4,9,14$, and $19{ }^{\circ} \mathrm{C}$, and calculated CUEs based on the amount of ${ }^{13} \mathrm{C}-\mathrm{CO}_{2}$ and ${ }^{13} \mathrm{C}-$ labelled microbial biomass produced. The effects of substrate, temperature, and metabolic conditions (representing
\end{abstract}

Responsible Editor: Ingrid Koegel-Knabner.

M. G. Öquist $(\varangle) \cdot$ B. Erhagen · M. Haei · U. Ilstedt •

M. B. Nilsson

Department of Forest Ecology \& Management, Swedish University of Agricultural Sciences (SLU), Skogsmarksgränd, SE-901 83 Umeå, Sweden

e-mail: mats.oquist@slu.se

B. Erhagen

Department of Ecology and Environmental Science, Umeå

University, SE-901 87 Umeå, Sweden

T. Sparrman

Department of Chemistry, Umeå University, SE-901 87 Umeå, Sweden

J. Schleucher

Department of Medical Biochemistry and Biophysics, Umeå University, SE-901 87 Umeå, Sweden unlimited substrate supply and substrate limitation) on CUE were evaluated.

Results CUE from metabolizing glucose was higher as compared to cellulose. A slight decrease in CUE with increasing temperature was observed in glucose amended samples (but only in the range 9-19 ${ }^{\circ} \mathrm{C}$ ), but not in cellulose amended samples. CUE differed significantly with metabolic conditions, i.e. CUE was higher during unlimited growth conditions as compared to conditions with substrate limitation.

Conclusions We conclude that it is integral to account for both differences in CUE during different metabolic phases, as well as complexity of substrate, when interpreting temperature dependence on CUE in incubation studies.

Keywords Carbon use efficiency (CUE) . Decomposition $\cdot$ Metabolic condition $\cdot \mathrm{NMR} \cdot{ }^{13} \mathrm{C}-$ substrate $\cdot$ Boreal forest soil

\section{Introduction}

The world's soils store very large quantities of carbon (3000 Pg; Tarnocai et al. 2009) several times the amount of $\mathrm{CO}_{2}-\mathrm{C}$ in the atmosphere. Therefore, even small changes in the soil carbon pool can have profound effects on atmospheric $\mathrm{CO}_{2}$ levels and, thus, the global climate (IPCC 2013; Schlesinger and Andrews 2000). The part of the $\mathrm{CO}_{2}$ soil flux originating from mineralization of $\mathrm{SOM}$ is controlled by microbial activity and how microorganisms partition the decomposition of OM between energy 
yielding processes associated with $\mathrm{CO}_{2}$ production (catabolic processes) and microbial biomass growth (anabolic processes).

This relationship between anabolic and catabolic activity is often represented in terms of carbon use efficiency (CUE), a measure of the proportion of the utilized carbon source that is converted into microbial biomass (del Giorgio and Cole 1998; Winzler and Baumberger 1938). Changes in the CUE of saprotrophic microorganisms in response to increases in temperature could potentially have large effects on overall terrestrial soil $\mathrm{CO}_{2}$ emissions. Moreover, it is vital to understand how the CUE varies with temperature in order to reliably quantify the associated feedback effects and their impact on climate change (Allison et al. 2010; Wetterstedt and Ågren 2011).

Previous studies have demonstrated that the CUE depends on a range of factors, including the temperature and nutrient availability, as well as the composition of the available carbon sources (Frey et al. 2013; Manzoni et al. 2012; Steinweg et al. 2008). The reason why CUE is sensitive to SOM composition is that the degradation of more complex SOM structures requires a greater number of enzymatic steps (Bosatta and Ågren 1999) and hence higher investment in enzymes and also higher activation energy (Bosatta and Ågren 1999), as compared to more readily available compounds.

The general understanding of how the CUE of saprotrophic bacteria and fungi is affected by temperature is that it decreases as the temperature increases (Farmer and Jones 1976; Hall and Cotner 2007; Mainzer and Hempfling 1976). This is primarily because the rate of maintenance respiration increases more rapidly than that of new microbial biomass production. The increased rate of maintenance respiration at higher temperatures is attributed to increases in the amount of energy required to maintain ion gradients across the cell membrane and to the increased rate of protein turnover (Farmer and Jones 1976; Hall and Cotner 2007; Mainzer and Hempfling 1976). Despite the general understanding of how CUE is affected by temperature, studies have demonstrated contradictive results, some studies showing a limited response to an increased temperature (Devevre and Horwath 2000; Dijkstra et al. 2011b) while others have shown a decreased CUE with increased temperature (Devevre and Horwath 2000; Frey et al. 2013; Steinweg et al. 2008). The comparatively large amount of energy required to decompose molecularly complex constituents of $\mathrm{OM}$ may also have a greater overall impact on the CUE than the temperature (Dijkstra et al. 2011b; Wetterstedt and Ågren 2011).

Empirical investigations into the relationship between CUE and the quality of the available organic material have primarily focused on feeding soil microorganisms with different carbon monomers (Dijkstra et al. 2011a; Drotz et al. 2010a; Frey et al. 2013; Shields et al. 1973) rather than carbon polymers. Because monomers can be taken up directly into the cell without the involvement of extracellular enzymes, which are required to degrade polymers, the CUE for the decomposition of monomers can be expected to be higher than for polymers. Thus, CUE derived from investigations based on mineralization of more complex, polymeric compounds should be more relevant for soil carbon dynamics than those derived from simple monomers.

Microbial growth requires a stoichiometric balance between carbon and other elements (especially nitrogen and phosphorus; Frost et al. 2006; Nordgren et al. 1988; Sinsabaugh et al. 2009). If the availability of other nutrients is below the stoichiometric requirements, there is a risk that excess carbon will be respired and converted into $\mathrm{CO}_{2}$ (or excreted in the form of organic compounds) rather than being used for biosynthesis, leading to reduced CUE (Ågren and Bosatta 1987; Manzoni and Porporato 2009). Thus, prevailing nutrient regime and the stoichiometric balance between carbon and nutrient availability should be an important factor determining CUE of the soil microbial population. It is conceivable that some of the inconsistency in the CUE data available in the literature (Devevre and Horwath 2000; Drotz et al. b; Frey et al. 2013; Steinweg et al. 2008) is due to differences in metabolic conditions at the time of estimating CUE (cf. Martens 1985). Principally, the main difference emanates from whether the conditions allow for microbial growth or not. This implies that CUE estimates are very dependent on the experimental conditions under which they were determined, for example, including factors such as amounts of substrate and nutrients added. Also under natural conditions soil substrate availability and nutrient regimes may vary considerably, both in space and time due to e.g. soil genesis, $\mathrm{N}$ deposition, plant species composition and phenology.

The aim of the study reported herein was to investigate how the CUE of saprotrophic microorganisms is affected by temperature and the complexity of the organic substrate. Further, we aimed at determine whether the CUE varies during the different metabolic phases as induced 
from addition and subsequent consumption of a carbon substrate together with required amounts of nitrogen and phosphorus. We incubated soil samples from the Ohorizon of a spodosol from a mixed boreal Scots Pine and Spruce forest at four temperatures $(4,9,14$, and $\left.19{ }^{\circ} \mathrm{C}\right)$. The soil samples were amended with either a carbon monomer $\left({ }^{13} \mathrm{C}\right.$-glucose $)$ or a carbon polymer $\left({ }^{13} \mathrm{C}\right.$-cellulose), and the CUE was calculated in each case by measuring the amount of respired ${ }^{13} \mathrm{C}-\mathrm{CO}_{2}$ and the synthesis of ${ }^{13} \mathrm{C}$-labelled microbial biomass. Glucose is the single most common C-monomer derived from biopolymers. Carbohydrate polymers, including cellulose, normally constitute $40-45 \%$ of the O-horizon in boreal forests (Drotz et al. 2010b; Erhagen et al. 2013), and glucose is the dominant monomer following cellulose hydrolysis. The ${ }^{13} \mathrm{C}-$ labelled substrates were added together with nutrients to allow unlimited growth (Nordgren 1992).

\section{Material and methods}

\section{Soil sampling and processing}

The soil used in this study was collected in September 2011 from the Kulbäcksliden experimental area in the Vindeln Experimental Forest, which is located in northern Sweden $\left(64^{\circ} 11^{\prime} \mathrm{N}\right.$. S $\left.19^{\circ} 33^{\prime} \mathrm{E}\right)$. The samples were taken from the organic horizon (O-horizon) of a spodosol, which is one of the major soil types in boreal forests (Soil Survey Staff 2003). The site was a mixed Scots pine (Pinus sylvestris. L.) and spruce (Picea abies. L.) forest. The ground vegtation was dominated by lingonberry (Vaccinium vitis idea) and bilberry (Vaccinium myrtillus) dwarf shrubs. The mean annual precipitation and temperature over the most recent climatic reference period (1961-1990) were $523 \mathrm{~mm}$ and $1.2{ }^{\circ} \mathrm{C}$, respectively (Alexandersson et al. 1991). Fresh litter and mosses were removed in the field and the samples were pooled to form a composite sample. In the laboratory, coarse roots and plant residues were removed and the soil was passed through a $5 \mathrm{~mm}$ mesh sieve, gently homogenizing the soil. Subsamples were dried at $105^{\circ} \mathrm{C}$ for $24 \mathrm{~h}$ to determine their dry mass, and the $\mathrm{OM}$ content was determined by loss on ignition (LOI; $550{ }^{\circ} \mathrm{C}$ for $6 \mathrm{~h}$ ). Prior to incubation, the water content of the fresh samples was adjusted to establish a water potential of $-25 \mathrm{kPa}$, which is known to be optimal incubation conditions in similar soil samples (Ilstedt et al. 2000). The OM content was
$0.93 \pm 0.004(\mathrm{SD}) \mathrm{kg} \mathrm{kg}^{-1}$ with a C content of $0.53 \mathrm{~kg} \mathrm{~kg}^{-1}$ and $\mathrm{N}$ content of $0.014 \mathrm{~kg} \mathrm{~kg}^{-1}$, the $\mathrm{C}: \mathrm{N}$ ration being 38. The composition of the $\mathrm{OM}$ (derived from $\mathrm{CP}$ MAS ${ }^{13} \mathrm{C}$ NMR spectra) were as follow: alkyl C, 26\%; methoxy-/N-alkyl, 6.5\%; O-alkyl, 37\%; di-Oalkyl, 11\%; aromatic C, 9\%; O-aromatic C, 6.6\% and Carbonyl C, 4\% (Erhagen et al. 2013).

Soil incubation and $\mathrm{CO}_{2}$ production measurements

A high-resolution respirometer (Respicond VI, Nordgren Innovations, Djäkneboda, Sweden) was used to measure hourly saprotrophic $\mathrm{CO}_{2}$ production rates from soil samples (Nordgren 1988). In the Respicond system, each incubation vessel is fitted with a small receptacle containing $10 \mathrm{ml} \mathrm{KOH}(0.5 \mathrm{M})$. All $\mathrm{CO}_{2}$ produced inside the vessel gets trapped in the $\mathrm{KOH}$ solution, reducing its electrical conductivity. The conductivity of the $\mathrm{KOH}$ solution is measured using platinum electrodes and used to determine the rate of $\mathrm{CO}_{2}$ production, which is expressed in units of $\mathrm{mg} \mathrm{CO}_{2} \mathrm{~g}^{-1}$ $\mathrm{OM}(\mathrm{dw}) \mathrm{h}^{-1}$. The version of the Respicond used had four different insulated water baths set to $4,9,14$, or $19^{\circ} \mathrm{C}$. The temperature in the baths is highly controlled and target temperature is maintained at $\pm 0.02{ }^{\circ} \mathrm{C}$ (Erhagen et al. 2013). 48 subsamples of soil (1 g OM dry weight (dw; corresponding to $1.06 \mathrm{~g}$ soil $\mathrm{dw}$ ) were placed in $250 \mathrm{ml}$ incubation vessels and incubated at one of four temperatures $\left(4,9,14\right.$, or $\left.19{ }^{\circ} \mathrm{C}\right)$. Twelve samples were incubated at each of the four temperatures; six were amended with ${ }^{13} \mathrm{C}$-glucose and six with ${ }^{13} \mathrm{C}$-cellulose (see below).

Carbon substrate additions and sampling for CUE determination

After a stable basal rate of respiration had been established (ca $200 \mathrm{~h}$ after the start of the incubation), $50 \mathrm{mg} \mathrm{C}$ of uniformly ${ }^{13} \mathrm{C}$-labelled glucose (IsoLife B.V., Wageningen, Netherlands; $>96 \%$ labelled) was added to half of the incubation vessels at each temperature and $50 \mathrm{mg} \mathrm{C}$ of uniformly ${ }^{13} \mathrm{C}$-labelled cellulose (IsoLife B.V., Wageningen, Netherlands; $>96 \%$ labelled) was added to the other half. The added amount of $\mathrm{C}$ thus corresponds to $10 \%$ of the organic $\mathrm{C}$ in the incubated sample. Alongside the labelled carbon substrates, nitrogen $\left(\mathrm{NH}_{4}\right)_{2} \mathrm{SO}_{4}$ and phosphorus $\left(\mathrm{KH}_{2} \mathrm{PO}_{4}\right)$ were added to all of the vessels to establish a $\mathrm{C}: \mathrm{N}$ : P mass ratio of 182:13:1 and thereby ensure the availability of sufficient nutrients 
to avoid limiting microbial growth (Nordgren et al. 1988). Glucose and cellulose were added as a fine powder and gently mixed with the soil samples to minimize disturbance (Nordgren et al. 1988), while the nutrients were dissolved in water before injected into the soil samples. The amount of addition of ${ }^{13} \mathrm{C}$-glucose and ${ }^{13} \mathrm{C}$-cellulose was chosen according to earlier work (Bergman et al. 1999; Lundberg et al. 2001; Drotz et al. 2010a) representing unlimited substrate supply for the microbial community as well as allowing for identification of new synthesized ${ }^{13} \mathrm{C}$-products based on the intensity differences between the ${ }^{13} \mathrm{C}$ addition and the natural abundance in the background soil (Drotz et al. 2010a). Both the consumption of the added ${ }^{13} \mathrm{C}$ labelled substrate and the synthesis of new ${ }^{13} \mathrm{C}$ labelled microbial biomass were followed by ${ }^{13} \mathrm{C}$ MAS NMR spectroscopy using samples from the soil incubations. For each of the labelled substrates, i.e. ${ }^{13} \mathrm{C}$ glucose and ${ }^{13} \mathrm{C}$ cellulose, 6 replicate soil samples were incubated at each temperature (see below). This made it possible to analyze both the consumption of the added ${ }^{13} \mathrm{C}$ labelled substrate and the synthesis of new ${ }^{13} \mathrm{C}$ labelled microbial biomass at six different points in time both during and after conditions of unlimited growth. The exact timing of soil sample collection for the analysis of substrate consumption and synthesis of ${ }^{13} \mathrm{C}$ labelled compounds was determined based on the real-time data on total $\mathrm{CO}_{2}$ production generated by the Respicond system (Fig. 1). The first two samples for the ${ }^{13} \mathrm{C}-$ glucose experiments were collected during the phase of unlimited growth. The time interval representing logarithmic growth, i.e. the phase used to estimate specific growth rate (SGR), was identified as the period with linear increase of log-transformed respired $\mathrm{CO}_{2}$, following Nordgren (1988). The third sample was collected when the $\mathrm{CO}_{2}$ production peaked (For $19^{\circ} \mathrm{C}$ the peak sample was missed, resulting in one additional sample after the peak) and the last three were collected at various points while the rate of $\mathrm{CO}_{2}$ production declined. In the ${ }^{13} \mathrm{C}$-cellulose experiments the number of samples collected for analysis varied because the decomposition of the ${ }^{13} \mathrm{C}$-cellulose was slow and because limited time of access to NMR only allowed analysis of a subset of time points. At $19^{\circ} \mathrm{C}$ the following samples were analyzed SGR1 (specific growth rate, SGR), AP1 (after peak), AP2, AP3. At $14{ }^{\circ} \mathrm{C}$ following samples were analyzed: SGR1, AP1, AP2, AP3, and AP4. At $9{ }^{\circ} \mathrm{C}$ three samples were analyzed: SGR1, AP1 and AP4. At $4{ }^{\circ} \mathrm{C}$ the following samples were analyzed: SGR1, Peak, AP1, AP2, AP3. AP4, and AP5. Immediately after each vessel being removed from the Respicond, the samples were added and thoroughly mixed with $500 \mu \mathrm{l}$ of $0.5 \% \mathrm{NaN}_{3}$ (Wolf et al. 1989) and stored in a freezer at $-20{ }^{\circ} \mathrm{C}$ until required for NMR analysis. The addition of $\mathrm{NaN}_{3}$ was done to inhibit further microbial activity (Drotz et al. 2010a).

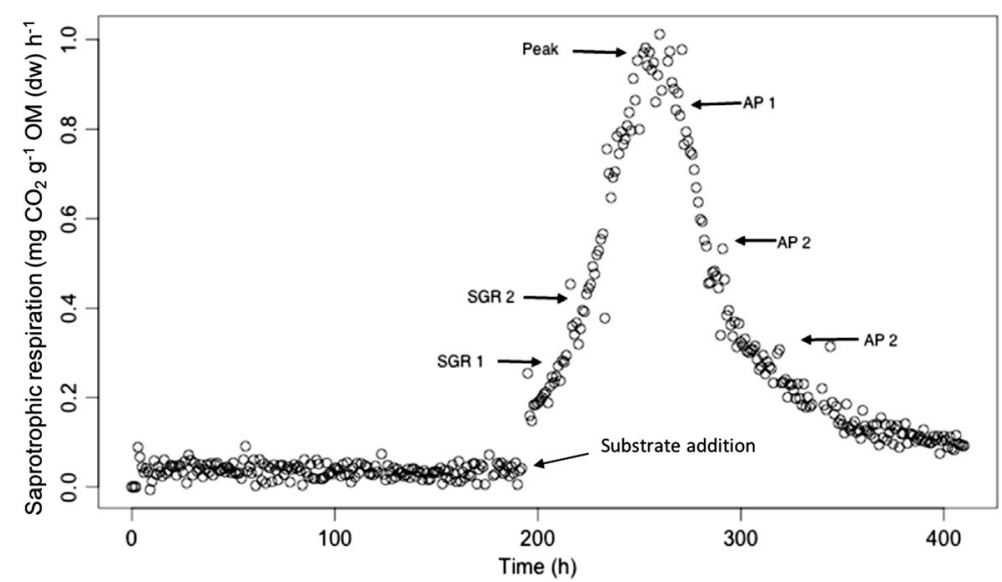

Fig. 1 A representative $\mathrm{CO}_{2}$ output profile for an incubation experiment conducted at $19{ }^{\circ} \mathrm{C}$ using ${ }^{13} \mathrm{C}$-glucose as the added carbon source. The arrows indicate the points in time and the corresponding metabolic phases at which samples were collected in order to determine the amount of respired ${ }^{13} \mathrm{CO}_{2}$, the amount of ${ }^{13} \mathrm{C}$-labelled substrate remaining and the amount of newly synthesized ${ }^{13} \mathrm{C}$-labelled compounds. In order to determine whether there were any statistically significant differences between the different metabolic phases in terms of CUE the samples were divided into two groups: a group consisting of the samples (specific growth rate) SGR1, SGR2, and peak samples; and a group consisting of the (after peak) AP1, AP2, and AP3 samples 
${ }^{13} \mathrm{C}$ magic-angle spinning NMR

A Varian/Chemagnetics CMX400 spectrometer with a ${ }^{13} \mathrm{C}$ operating frequency of $100.72 \mathrm{MHz}$ was used to analyze the incubated soil samples for microbial compounds synthesized from the added substrates. Prior to NMR analysis, the soil was thawed and the wet samples were packed into 4-mm MAS rotors. The packed rotors were then placed in the spectrometer's magnet and spun at $8 \mathrm{kHz}$ at the magic angle $\left(54.7^{\circ}\right)$ to remove inhomogeneous broadening. The ${ }^{13} \mathrm{C}$ spectra were collected with direct polarization using an $11 \mu \mathrm{s} 90^{\circ}$ pulse followed by continuous wave $1 \mathrm{H}$ decoupling at $48 \mathrm{kHz}$ during acquisition. The acquisition time was $41 \mathrm{~ms}$ with a relaxation delay of $4 \mathrm{~s}$, and 3800 scans were accumulated. To remove the small ${ }^{13} \mathrm{C}$ background signal originating from the natural ${ }^{13} \mathrm{C}$ content of the soil and the Teflon spacers within the MAS rotor, a free induction decay (FID) was recorded for a soil sample with no added ${ }^{13} \mathrm{C}$ labelled compounds. This FID was then subtracted from the sample FIDs prior to Fourier transformation.

Identification of the compounds observed by ${ }^{13} \mathrm{C}$ MAS NMR

Several literature sources were used to determine the composition of the ${ }^{13} \mathrm{C}$-labelled microbial compounds that were identified in the ${ }^{13} \mathrm{C}$ MAS NMR experiments (Fan and Lane 2008; Sattler et al. 1999; Strandberg et al. 2001). In the spectra the acyl chain region agreed well to the chemical shift of the phospholipid dioleoylphosphatidylcholine (DOPC) (Strandberg et al. 2001) and the presence of a carboxyl signal at $172.3 \mathrm{ppm}$ showed that these fatty acids formed from the labeled substrate were ester bound to a backbone and not free fatty acids. The acyl chain in the lipids had the following chemical shifts with reference to the corresponding 18 carbons along the oleoyl chain: $14.7 \mathrm{ppm}$ (C18), $23.3 \mathrm{ppm}$ (C17), 25.5 ppm (C3), 27.9 ppm (C8 and C11), $30.3 \mathrm{ppm}$ (C4-C7 and C12-15), 32.5 ppm (C16), 34.4 ppm (C2), 130.5 ppm (C9-C10), and 172.3 ppm (C1).

${ }^{13} \mathrm{C}-\mathrm{CO}_{2} \mathrm{NMR}$ analyses

The production of ${ }^{13} \mathrm{C}-\mathrm{CO}_{2}$ during the incubation experiments was determined by performing solution ${ }^{13} \mathrm{C}$ NMR analyses of the $\mathrm{KOH}$ solutions from the Respicond apparatus. A subsample $(250 \mu \mathrm{l})$ of the $10 \mathrm{~mL}$ of $\mathrm{KOH}$ solution in the Respicond was mixed with $250 \mu$ of a stock solution containing $1.00 \mathrm{M}$ potassium acetate and $20 \% \mathrm{D}_{2} \mathrm{O}$ in a $5 \mathrm{~mm}$ NMR tube (giving a final potassium acetate concentration of $0.5 \mathrm{M}$ in the NMR tube). Quantitative ${ }^{13} \mathrm{C}$ NMR analyses were performed using a Bruker Avance III HD $600 \mathrm{MHz}$ spectrometer equipped with a $5 \mathrm{~mm}$ TCI HCP cryoprobe with cold ${ }^{13} \mathrm{C}$ and ${ }^{1} \mathrm{H}$ preamplifiers. The carbon spectra were acquired at 150.9 MHz using a $90^{\circ}{ }^{13} \mathrm{C}$ excitation pulse of $15.5 \mu \mathrm{s}$ followed by low power ${ }^{1} \mathrm{H}$ WALTZ16 decoupling of the acetate protons during acquisition. To enable quantitative analysis of the carbon signals, the relaxation delay was set to $300 \mathrm{~s}$ because of the long $\mathrm{T}_{1}$ relaxation time of the carbonate $\left(\mathrm{T}_{1}=55 \mathrm{~s}\right.$ as determined by an inversion recovery experiment). In addition, the ${ }^{13} \mathrm{C}$ carrier was centered between the acetate peak at $181 \mathrm{ppm}$ and the carbonate signal at $168 \mathrm{ppm}$ to guarantee equivalent excitation. Using these settings, a signal-to-noise ratio of about 140:1 was typically achieved after 8 scans for the $500 \mathrm{mM}$ acetate reference at natural abundance, with a similar or better signal to noise ratio for the ${ }^{13} \mathrm{C}-$ enriched carbonate of interest. The actual ${ }^{13} \mathrm{C}$ carbonate content was then calculated by signal integration, using appropriate scaling factors to account for the effects of dilution and the natural abundance of ${ }^{13} \mathrm{C}$ in the acetate reference material.

\section{Data analysis}

The CUE was determined according to Drotz et al. (2010a), using the ${ }^{13} \mathrm{C}$ MAS NMR data to determine the mass of carbon in the newly synthesized ${ }^{13} \mathrm{C}-$ compounds (i.e. after subtracting the signal of the added substrate) and the solution-phase NMR data to measure the amount of ${ }^{13} \mathrm{C}-\mathrm{CO}_{2}$ produced:

$C U E=\frac{\text { Newly synthesized }{ }^{13} \mathrm{C} \text { compounds }}{\left(\text { Newly synthesized }{ }^{13} \mathrm{C} \text { compunds }+{ }^{13} \mathrm{C}-\mathrm{CO}_{2}\right)}$

The consumption of substrates and production of synthesized ${ }^{13} \mathrm{C}$ compounds over time were evaluated by regressions using a best-fit approach. The consumption of glucose and cellulose were best described by a negative exponential function, while the production of new compounds were best described by a logarithmic function where rates of increase leveled off at the end of the incubations. In some cases, especially at the lower 
temperatures, the change over time could be equally well explained by a linear function. However, since it is likely that the responses observed still were in the linear part of a logarithmic relationship (and that rates would level off if we had incubated over longer times), the logarithmic functions were used to maintain consistency.

A Students t-test was used to evaluate differences in CUE based on substrate type (averaged over all metabolic phases). A two-way ANOVA was then performed for each substrate to investigate the combined effect of temperature and metabolic phases (Fig. 1) on CUE. The CUEs before and at the peak (i.e. SGR1. SGR2 and peak samples; Fig. 1) were compared to those observed after the peak (i.e. AP1, AP2 and AP3; Fig. 1). In the twoway ANOVA the CUE values were treated as dependent variable and temperature and metabolic status as independent variables, and also the interaction between the independent variables were included in the model. The statistical analyses were performed using JMP 10.0 (SAS Institute Inc., Cary, NC, USA).

\section{Results}

Carbon use efficiency

The CUE values averaged over all metabolic phases for microbial populations supplied with the carbon monomer $\left({ }^{13} \mathrm{C}\right.$-glucose; average $\left.0.70 \pm 0.11 \mathrm{SD}, n=6\right)$ were significantly higher $(p=0.001)$ than those for samples supplied with a carbon polymer $\left({ }^{13} \mathrm{C}\right.$-cellulose; average

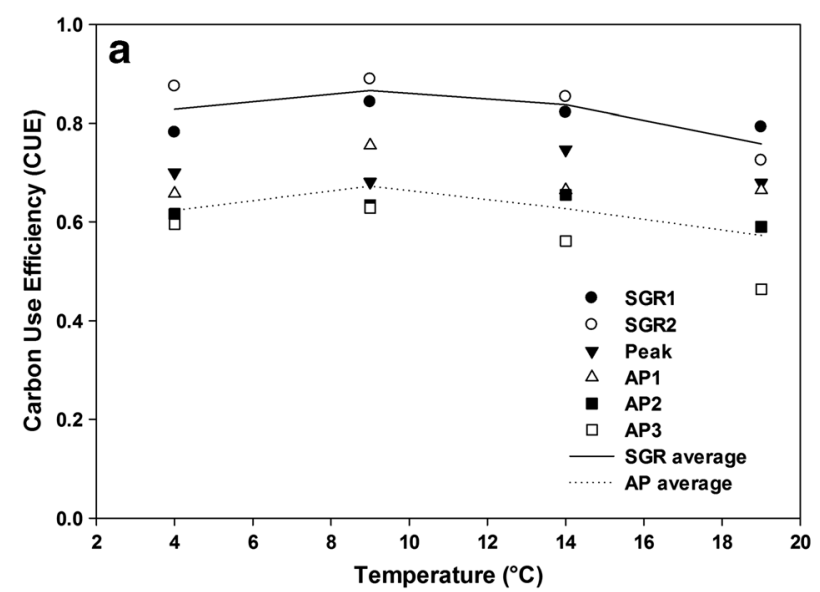

Fig. 2 CUE for the different metabolic phases during the decomposition of the labelled substrates ${ }^{13} \mathrm{C}$-glucose (a) and ${ }^{13} \mathrm{C}$-cellulose (b) at each of the four incubation temperatures. The different
$0.55 \pm 0.13 \mathrm{SD}, n=6)$ ), as well as during the period of exponential growth (SGR; $p=0.01, n=12$ ) and after the peak $(p=0.007, n=12)$. In the glucose experiments, the CUE up to to peak respiration was $0.78( \pm$ SE 0.02$)$ while that for the cellulose experiments was $0.68( \pm \mathrm{SE}$ $0.01, n=4)$. After the rate of respiration had peaked, the average CUE for the glucose experiments was 0.62 $( \pm$ SE $0.07, n=11)$ while that for cellulose was 0.51 ( \pm SE 0.03 ). In addition, the CUE before the rate of respiration peaked was consistently higher than that after the peak for both substrates $(p<0.001$ for glucose and $p=0.008$ for cellulose).

In glucose amended samples there was trend in decreasing CUE with increasing temperature, but only in the range from 9 to $19^{\circ} \mathrm{C}$, as revealed by their correlation $(r=-0.5 ; p=0.05 ;$ Fig. $2 \mathrm{a})$. For cellulose CUE no correlation between temperature and CUE could be observed. (Fig. 2b). Analyzing the combined effect of temperature and metabolic phase on CUE in the glucose amended samples (two-way ANOVA; $\mathrm{R}^{2}=0.58$ ) the metabolic phase contribute significantly $(p<0.001)$, while temperature did not $(p=0.19)$. Confining the analysis to the temperature range of 9 to $19^{\circ} \mathrm{C}$, where CUE and temperature were correlated, did not change this picture (although the $p$-value for temperature decreased to 0.13). The same pattern was revealed for cellulose CUE $\left(\mathrm{R}^{2}=0.34\right)$ where metabolic phase contributed significantly $(p=0.01)$ while temperature did not $(p=0.52)$. The interaction term between temperature and metabolic phase was not significant for either of the two models.

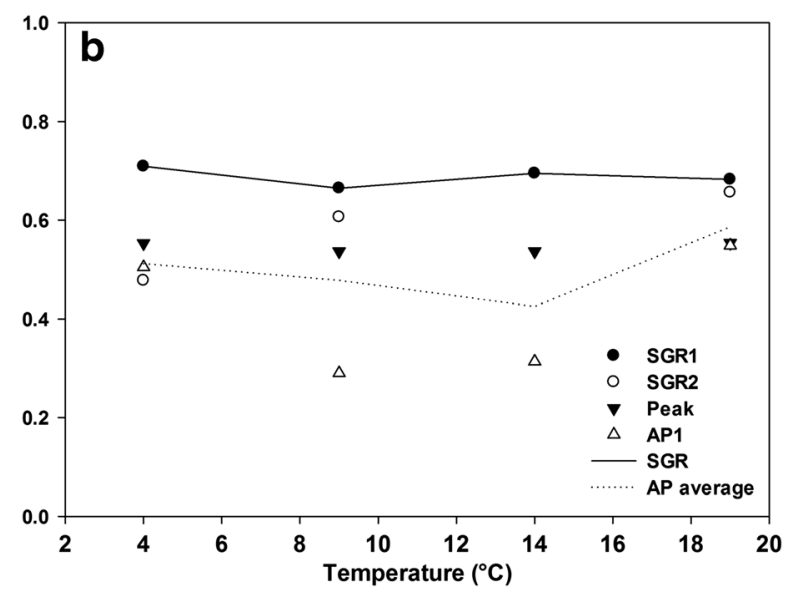

symbols (see Fig. 1 for explanation of the symbol labeling) represent samples taken during the different metabolic phases during the incubation period 
Microbial utilization of the ${ }^{13} \mathrm{C}$ labelled substrates

The ${ }^{13} \mathrm{C}$-labelled microbial compounds resulting from new microbial synthesis were quantified by integrating the NMR spectra's (Tables 1 and 2). During the incubation experiments, the decline in the measured concentrations of the labelled glucose correlated well with predictions based on the assumption of a negative exponential function at all studied temperatures (Fig. 3a). Notably, the amount of the labelled glucose was still quite high $(7 \mathrm{mM})$ when the rate of respiration peaked and the rate of $\mathrm{CO}_{2}$ production became substrate-limited. The main compounds synthesized by the microorganisms using the labelled material were polymeric carbohydrates and acyls (lipids) (Tables 1 and 2). The chemical shift observed in the NMR spectra in the acyl region in samples amended with glucose corresponded well to those of phospholipid fatty acids (PLFAs) (Drotz et al. 2010a). The increase in ${ }^{13} \mathrm{C}$-lipid concentrations in the soil samples over time could best be explained by a logarithmic function (Fig. 3b). There was an evident production of $\mathrm{C} 1(\alpha)$ carbohydrate polymers from the added glucose, but there was no significant relationship between the measured amount and time (Table 1). When ${ }^{13} \mathrm{C}$ labelled cellulose was used as a substrate, its abundance declined over time, as the ${ }^{13} \mathrm{C}$-cellulose was decomposed (Fig. 3c). The amount of ${ }^{13} \mathrm{C}$-cellulose at $19{ }^{\circ} \mathrm{C}$ and $4{ }^{\circ} \mathrm{C}$ respectively decreased significantly according to a negative exponential function $(p=0.003$, $n=4 ; p=0.006, n=6$; Fig. $3 \mathrm{c}$ ) but not during incubations at $14{ }^{\circ} \mathrm{C}$ or $9{ }^{\circ} \mathrm{C}$. The production of lipids resulting from the decomposition of cellulose increased significantly according to a logarithmic function at $4{ }^{\circ} \mathrm{C}$ but not at the other temperatures (Fig. 3d). At the end of the incubations $55-60 \%$ of the added ${ }^{13} \mathrm{C}$-cellulose remained intact, while the corresponding amount of ${ }^{13} \mathrm{C}$-glucose was $10 \%$ (Table 2).

\section{Discussion}

Our results show that the substrate complexity and microbial metabolic state exert master controls on CUE while temperature has a minor influence. This observation is also analogue to the results indicated by Martens (1985) after addition of ${ }^{14} \mathrm{C}$ labelled glucose and cellulose to clay rich mineral soil samples, where a relatively larger fraction of the substrate was observed in microbial biomass from glucose, as compared to cellulose (although results were somewhat confounded by the fumigation technique used to account for microbial biomass). The significantly lower CUE for a carbon polymer than for a carbon monomer is in accordance with the general understanding that more complex compounds require more energy for decomposition and, thus, yield a lower overall CUE (Ågren et al. 2001; Manzoni et al. 2012). The higher energy demand associated with mineralization of polymers, in comparison to monomers, emanates from the requirement of exoenzyme production enabling polymer hydrolysis prior to uptake (Manzoni et al. 2012). Another substrate related difference when comparing CUEs from monomers with polymers relates to substrate supply rate, which conceivably is higher for glucose than for cellulose, since the latter is dependent on diffusion of expenzymes to the susbstrate surface, the concomitant hydrolysis and then diffusion of the liberated glucose (or cellobiose) to the cell before it can be used metabolically. A low substrate supply rate results in a higher fraction of the available substrate being metabolically used for maintenance, rather than growth. This also agrees well with decreasing CUEs with time in glucose amended soil samples as samples move towards substrate limitation.

It is likely that the CUE values determined by using polymeric substrates in incubation experiments will be more directly relevant to the decomposition of SOM under field conditions than those obtained using monomeric substrates because practically all soil carbon exists as polymers. Indeed, models of SOM decomposition based on studies that use monomers alone may overestimate a CUE value (Sinsabaugh et al. 2013), which agrees with our findings with the CUE of glucose being significantly higher than of cellulose. Another substrate quality-related factor that affects the CUE is that different monomers are metabolized via different metabolic pathways and therefore yield different respiration rates per unit carbon assimilated, i.e. CUE (Gommers et al. 1988; Gottschalk 1986; Manzoni et al. 2012; van Hees et al. 2005). However, in this study the compounds taken up by the microorganisms would have been either monomeric glucose or cellobiose produced by the enzymatic cleavage of cellulose. It is therefore likely that the metabolic pathways used to degrade the monomer would have been very similar to those for the polymer (Gottschalk 1986).

We also found that CUE varied substantially with different metabolic phases for both monomeric and polymeric substrates (Fig. 2, Tables 1 and 2). In general, 
Table 1 The amounts of ${ }^{13} \mathrm{C}$ compounds, ${ }^{12} \mathrm{C}-\mathrm{CO}_{2}$ and calculated CUE at the different metabolic conditions resulting from degradation of added ${ }^{13} \mathrm{C}$-glucose

\begin{tabular}{|c|c|c|c|c|c|c|c|c|c|c|}
\hline $\begin{array}{l}\text { Sample } \\
\text { ID }^{\mathrm{b}}\end{array}$ & $\begin{array}{l}\text { Time }^{\mathrm{c}} \\
\text { (h) }\end{array}$ & $\begin{array}{l}\text { Temp. } \\
\left({ }^{\circ} \mathrm{C}\right)\end{array}$ & $\begin{array}{l}\text { Glucose }^{\mathrm{a}, \mathrm{e}} \\
(\mathrm{mg})\end{array}$ & $\begin{array}{l}\text { C1(alpha) })^{\mathrm{a}, \mathrm{f}} \\
(\mathrm{mg})\end{array}$ & $\begin{array}{l}\mathrm{C} 1 \text { (beta) })^{\mathrm{a}, \mathrm{g}} \\
(\mathrm{mg})\end{array}$ & $\begin{array}{l}\text { Tot Lipid } \\
\text { (mg) }\end{array}$ & $\begin{array}{l}{ }^{13} \mathrm{C} \text { synth. } \\
(\mathrm{mg})\end{array}$ & $\begin{array}{l}{ }^{13} \mathrm{C}-\mathrm{CO}_{2}{ }^{\mathrm{j}} \\
(\mathrm{mg})\end{array}$ & $\begin{array}{l}{ }_{(\mathrm{mg})} \mathrm{C}-\mathrm{CO}_{2}{ }^{\mathrm{k}} \\
(\mathrm{m})\end{array}$ & CUE \\
\hline SGR1 & 23 & 19 & 40.7 & 3.5 & 2.2 & 1.5 & 7.4 & 1.9 & 0.6 & 0.80 \\
\hline SGR2 & 41 & 19 & 30.5 & 3.4 & 1.6 & 2.8 & 14.1 & 5.4 & 1.1 & 0.72 \\
\hline Peak & 51 & 19 & 24.6 & 5.1 & 2.9 & 7.5 & 17.3 & 8.2 & 0.8 & 0.68 \\
\hline AP2 & 66 & 19 & 24.3 & 4.5 & 2.7 & 7.3 & 17.1 & 8.6 & 1.0 & 0.66 \\
\hline AP3 & 152 & 19 & 12.3 & 5.5 & 3,9 & 9.8 & 22.2 & 15.5 & 1.0 & 0.59 \\
\hline AP4 & 220 & 19 & 7.8 & 3.7 & 2.7 & 7.7 & 15.1 & 17.6 & 0.7 & 0.46 \\
\hline SGR1 & 23 & 14 & 43.3 & 2.1 & 0.9 & 0.8 & 5.5 & 1.2 & 1.1 & 0.82 \\
\hline SGR2 & 41 & 14 & 35.6 & 3.9 & 2.1 & 1.1 & 12.3 & 2.1 & 1.6 & 0.85 \\
\hline Peak & 58 & 14 & 28.3 & 4.4 & 1.2 & 6.7 & 16.2 & 5.5 & 1.3 & 0.75 \\
\hline AP1 & 99 & 14 & 15.9 & 5.9 & 2.3 & 13.2 & 22.6 & 11.4 & 5.4 & 0.66 \\
\hline AP2 & 152 & 14 & 10.9 & 4.4 & 2.3 & 12.1 & 25.6 & 13.5 & 1.3 & 0.65 \\
\hline AP3 & 220 & 14 & 4.4 & 4.1 & 2.6 & 14.9 & 25.6 & 20.0 & 1.8 & 0.56 \\
\hline SGR1 & 21 & 9 & 45.1 & 2.0 & 0.8 & 0.02 & 4.1 & 0.8 & 0.9 & 0.84 \\
\hline SGR2 & 39 & 9 & 35.0 & 2.2 & 0.7 & 0.4 & 13.4 & 1.7 & 1.2 & 0.89 \\
\hline Peak & 77 & 9 & 33.1 & 2.3 & 0.7 & 4.3 & 11.5 & 5.4 & 2.0 & 0.68 \\
\hline AP1 & 97 & 9 & 25.3 & 5.2 & 3.3 & 5.1 & 18.7 & 6.1 & 2.5 & 0.76 \\
\hline AP2 & 165 & 9 & 15.4 & 4.2 & 2.2 & 12.5 & 22.0 & 12.7 & 2.8 & 0.63 \\
\hline AP3 & 242 & 9 & 2.8 & 4.5 & 2.6 & 17.1 & 29.6 & 17.6 & 8.0 & 0.63 \\
\hline SGR1 & 39 & 4 & 45.6 & 2.0 & 1.0 & 0.1 & 3.5 & 1.0 & 3.2 & 0.78 \\
\hline SGR2 & 56 & 4 & 36.9 & 1.6 & 0.5 & 0.6 & 11.5 & 1.7 & 3.3 & 0.87 \\
\hline Peak & 102 & 4 & 31.8 & 3.8 & 1.3 & 5.0 & 12.8 & 5.5 & 2.4 & 0.70 \\
\hline AP1 & 165 & 4 & 11.0 & 6.6 & 4.0 & 12.1 & 25.6 & 13.4 & 3.3 & 0.66 \\
\hline AP2 & 202 & 4 & 5.9 & 4.0 & 1.5 & 15.9 & 27.2 & 16.9 & 2.9 & 0.62 \\
\hline AP3 & 314 & 4 & 4.9 & 4.8 & 3.2 & 16.1 & 26.8 & 18.3 & 5.4 & 0.60 \\
\hline
\end{tabular}

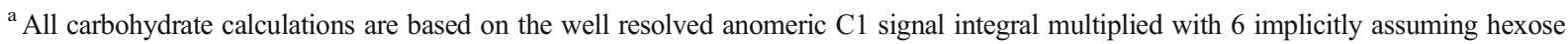
monomers

${ }^{b}$ The samples collected for analysis of the consumption and synthesis of ${ }^{13} \mathrm{C}$ labelled compounds. The time for sample collection was determined based on the real-time data on total $\mathrm{CO}_{2}$ production generated by the Respicond system (Fig. 1)

${ }^{\mathrm{c}}$ The time in hours of the incubation before being removed from the Respicond and sterilized by addition of sodium azide $\left(\mathrm{NaN}_{3}\right)$

d The incubation temperature in ${ }^{\circ} \mathrm{C}$

${ }^{\mathrm{e}}$ The amount of glucose derived for the NMR spectra from the sum of C1(alpha) (92.9 ppm) and C1(beta) (96.9 ppm)

${ }^{\mathrm{f}}$ The amount of polymeric carbohydrates with $\mathrm{C} 1$ (alpha) $\rightarrow \mathrm{C} 4$ linkage (100.7 ppm) e.g. starch and glycogen

${ }^{\mathrm{g}}$ The amount of polymeric carbohydrates with $\mathrm{C} 1$ (beta) $\rightarrow \mathrm{C} 4$ linkage (104.0 ppm) e.g. cellobiose and cellulose

${ }^{\mathrm{h}}$ The amount of lipids derived from integrating the alkyl carbon region $(0-50 \mathrm{ppm})$ in the spectra's

${ }^{\mathrm{i}}$ The total amount of $13 \mathrm{C}$ detected in the samples by NMR after subtracting the amount of remaining glucose

${ }^{\mathrm{j}}$ The amount of ${ }^{13} \mathrm{CO}_{2}$ trapped in the $\mathrm{KOH}$ and analyzed by ${ }^{13} \mathrm{C}$ - NMR

${ }^{\mathrm{k}}$ The amount of ${ }^{12} \mathrm{CO}_{2}$ calculated as the difference between the amount of ${ }^{13} \mathrm{CO}_{2}$ and the total accumulated $\mathrm{CO}_{2}$

${ }^{1}$ The calculated CUE (Eq. 1)

the CUE observed during exponential growth conditions, i.e. before the $\mathrm{CO}_{2}$ production peaked were significantly higher than those after the peak. This highlights the importance of substrate availability and stoichiometric relations to other essential elements (e.g. N, P) on metabolic partitioning (Spohn 2014; Sterner and Elser 2002) and should be considered when estimating and extrapolating empirically derived CUE 
Table 2 The amounts of ${ }^{13} \mathrm{C}$ compounds, ${ }^{12} \mathrm{C}-\mathrm{CO}_{2}$ and calculated $\mathrm{CUE}$ at the different metabolic conditions resulting from degradation of added ${ }^{13} \mathrm{C}$-cellulose

\begin{tabular}{|c|c|c|c|c|c|c|c|c|}
\hline $\begin{array}{l}\text { Sample } \\
\text { ID }^{\mathrm{b}}\end{array}$ & $\begin{array}{l}\text { Temp. } \\
\left({ }^{\circ} \mathrm{C}\right)\end{array}$ & $\begin{array}{l}\text { Time }(h)^{d} \\
(h)\end{array}$ & $\begin{array}{l}\text { C1(beta) cellulose } \mathrm{e}^{\mathrm{a}, \mathrm{e}} \\
(\mathrm{mg})\end{array}$ & $\begin{array}{l}\text { Tot Alkyl } \\
(\mathrm{mg})\end{array}$ & $\begin{array}{l}{ }^{13} \mathrm{C} \text { synth. } \\
(\mathrm{mg})\end{array}$ & $\begin{array}{l}{ }_{(\mathrm{mg})} \mathrm{C}-\mathrm{CO}_{2}{ }^{\mathrm{h}} \\
{ }^{13}\end{array}$ & $\begin{array}{l}{ }_{(\mathrm{mg})} \mathrm{C}-\mathrm{CO}_{2}{ }^{\mathrm{i}} \\
\end{array}$ & $\mathrm{CUE}^{\mathrm{j}}$ \\
\hline SGR1 & 19 & 169 & 40.4 & 1.8 & 6.8 & 2.8 & 13.3 & 0.71 \\
\hline AP1 & 19 & 289 & 37.2 & 2.4 & 6.1 & 6.7 & 22.8 & 0.48 \\
\hline AP2 & 19 & 361 & 36.2 & 2.1 & 7.6 & 6.2 & 25.5 & 0.55 \\
\hline AP3 & 19 & 517 & 33.1 & 2.4 & 8.5 & 8.4 & 31.9 & 0.50 \\
\hline SGR1 & 14 & 180 & 47.6 & 0.9 & 1.9 & 0.5 & 13.4 & 0.79 \\
\hline AP1 & 14 & 218 & 40.9 & 1.6 & 6.0 & 3.0 & 17.1 & 0.67 \\
\hline AP2 & 14 & 363 & 34.6 & 2.6 & 9.3 & 6.1 & 23.1 & 0.60 \\
\hline AP3 & 14 & 420 & 35.1 & 0.4 & 8.5 & 6.4 & 32.7 & 0.57 \\
\hline AP4 & 14 & 561 & 37.5 & 3.6 & 3.6 & 8.9 & 29.4 & 0.29 \\
\hline SGR1 & 9 & 215 & 43.3 & 1.5 & 4.6 & 2.0 & 20.4 & 0.70 \\
\hline AP1 & 9 & 738 & 34.9 & 3.3 & 8.1 & 7.0 & 41.3 & 0.54 \\
\hline AP4 & 9 & 859 & 38.4 & 3.1 & 3.6 & 8.0 & 46.6 & 0.31 \\
\hline SGR1 & 4 & 145 & 53.4 & 1.3 & - & 0.7 & 11.6 & - \\
\hline SGR2 & 4 & 310 & 42.7 & 1.9 & 5.0 & 2.3 & 19.3 & 0.68 \\
\hline AP1 & 4 & 479 & 37.8 & 2.4 & 8.0 & 4.2 & 18.3 & 0.66 \\
\hline AP3 & 4 & 630 & 36.6 & 2.5 & 7.4 & 6.0 & 21.3 & 0.55 \\
\hline AP4 & 4 & 745 & 37.7 & 3.2 & 5.4 & 6.8 & 21.1 & 0.44 \\
\hline AP5 & 4 & 858 & 32.0 & 3.1 & 9.8 & 8.1 & 18.9 & 0.55 \\
\hline
\end{tabular}

$\overline{{ }^{a} \text { All carbohydrate calculations are based on the well resolved anomeric } \mathrm{C} 1 \text { signal integral multiplied with } 6 \text { implicitly assuming hexose }}$ monomers

${ }^{\mathrm{b}}$ The samples collected for analysis of the consumption and synthesis of ${ }^{13} \mathrm{C}$ labelled compounds, which was determined based on the realtime data on total $\mathrm{CO}_{2}$ production generated by the Respicond system (Fig. 1)

${ }^{\mathrm{c}}$ The time in hours of the incubation before being removed from the Respicond and sterilized nitrate acid $\left(\mathrm{NaN}_{3}\right)$

${ }^{\mathrm{d}}$ The incubation temperature in ${ }^{\circ} \mathrm{C}$

${ }^{\mathrm{e}}$ The amount of polymeric carbohydrates derived for the NMR spectra with C1(beta) $\rightarrow$ C4 linkage (104.0 ppm) e.g. cellobiose and cellulose

${ }^{\mathrm{f}}$ The amount of alkyl-C derived from the alkyl carbon region (integrals within, 0-50 ppm) e.g. lipids

${ }^{\mathrm{g}}$ The total amount of $13 \mathrm{C}$ detected in the samples by NMR after subtracting the amount of remaining glucose

${ }^{\mathrm{h}}$ The amount of ${ }^{13} \mathrm{C}-\mathrm{CO}_{2}$ trapped in the $\mathrm{KOH}$ and analyzed by ${ }^{13} \mathrm{C}-\mathrm{NMR}$

${ }^{\mathrm{i}}$ The amount of ${ }^{12} \mathrm{C}-\mathrm{CO}_{2}$ calculated as the difference between the amount of ${ }^{13} \mathrm{C}-\mathrm{CO}_{2}$ and the total accumulated $\mathrm{CO}_{2}$

${ }^{\mathrm{j}}$ The calculated CUE (Eq. 1)

values. The rate of utilization of glucose decayed exponentially towards the end of the experiment (Fig. 3a) indicating that the rate of respiration had become limited by substrate availability. It should be noted that even if substrate availability was limiting metabolism the glucose concentration in the soil solution was still relatively high at around $7 \mathrm{mM}$. This may reflect a limitation arising from the constraints on e.g. substrate diffusion through the soil matrix, which might explain why the CUE decreased over time after $\mathrm{CO}_{2}$ production peaked (Hall and Cotner 2007). In contrast, the rate of utilization for the polymer decreased more linearly (Fig. 3c) over time, suggesting that conditions of substrate supply was more uniform over the course of the incubations as compared to the samples amended with glucose.

Concerning the effect of temperature on CUE there was a significant apparent decrease in CUE after adding glucose when going from 9 to $19^{\circ} \mathrm{C}$ and this agrees with the general theory and with other studies (Farmer and Jones 1976; Frey et al. 2013; Hall and Cotner 2007; Steinweg et al. 2008). However, for the carbon polymer 

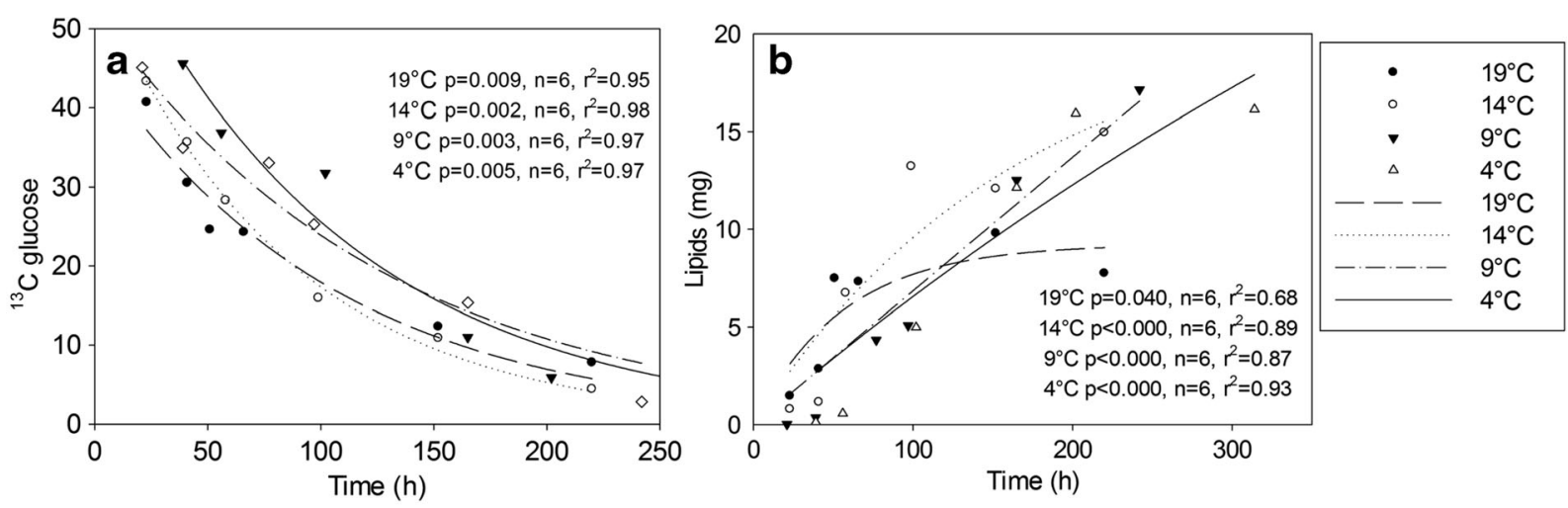
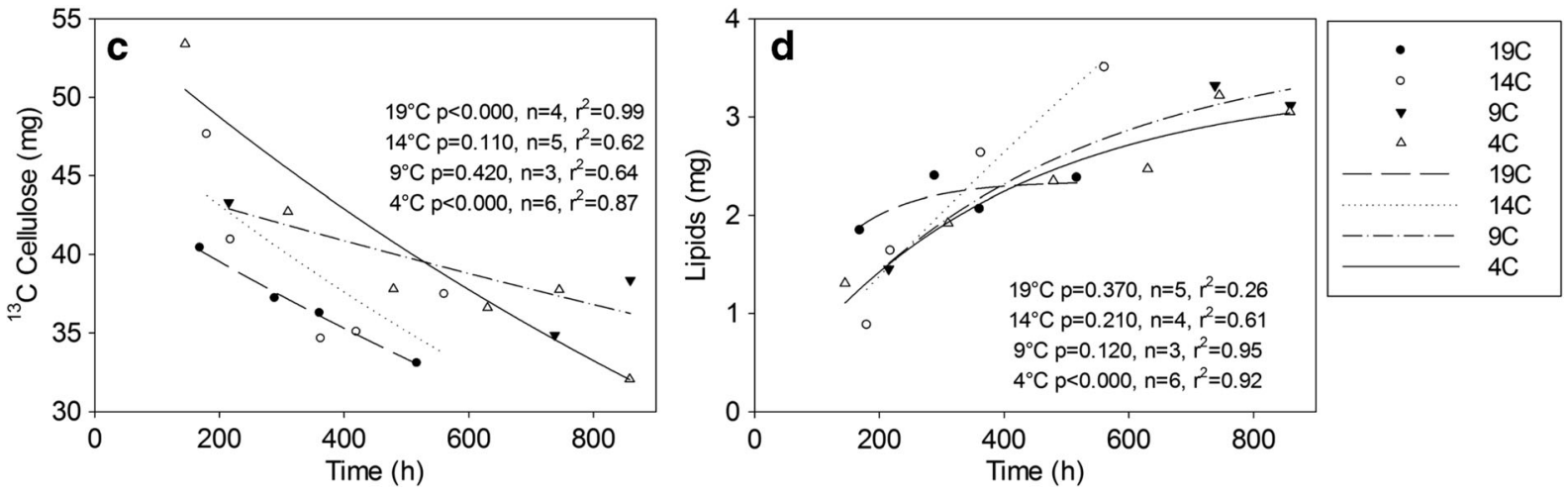

Fig. 3 Microbial consumption and production of ${ }^{13} \mathrm{C}$-labelled carbon compounds over time following the addition of ${ }^{13} \mathrm{C}-$ glucose $(\mathbf{a}, \mathbf{b})$ and ${ }^{13} \mathrm{C}-$ cellulose $(\mathbf{c}, \mathbf{d})$. The measured concentrations

$\left({ }^{13} \mathrm{C}\right.$-cellulose $)$ there was no significant effect of temperature on CUE. Such contradictory results have also been described by Steinweg et al. (2008) and Frey et al. (2013), who observed a decreased CUE for the decomposition with increased temperature, while Frey et al. (2013) also found that the CUE values for soil samples amended with glucose or oxalic acid did not change with the temperature. In addition, Drotz et al. (2010a) reported that the CUE of glucose exhibited no temperature dependence at temperatures of $+9,+4$ and $-4{ }^{\circ} \mathrm{C}$. Our results clearly reveals the seemingly "apparent" effect of temperature on CUE in fact emanates entirely from an indirect temperature effect through shifting the metabolic phases in time. For example, after substrate addition to samples at high temperatures the microbial community will go through the metabolic phases more rapidly as compared to samples at lower temperatures. The use of two-way ANOVA clearly revealed that after accounting for the effect of metabolic phases there was no effect from temperature at all on the CUE.

The use of ${ }^{13} \mathrm{C}$ MAS NMR spectroscopy allowed us not only to quantify the anabolic activity of the soil of ${ }^{13} \mathrm{C}$-glucose and ${ }^{13} \mathrm{C}$-cellulose (panel a, c) were fitted to a negative exponential function. The buildup of lipids were fitted a logarithmic function (panel $\mathbf{b}, \mathbf{d}$ )

microorganisms but also enabled us to determine which compounds had been synthesized. The allocation of the labelled carbon to new microbial synthesized compounds was relatively temperature independent aside from the longer time constants observed for the lower temperatures. Ladd et al. (1981) found that after amending mineral soil samples with ${ }^{14} \mathrm{C}$ labelled plant biomass, the amount of label detected as microbial biomass quickly increased during the initial 4 weeks of incubation and peaked after $4-8$ weeks. This is consistent with our observation of microbial incorporation of the ${ }^{13} \mathrm{C}$-cellulose that typically leveled off after $3-$ 4 weeks. The distinguishable compounds that are most strongly associated with microbial growth are membrane lipids (PLFAs, Drotz et al. 2010a.). During the incubation experiments the concentration of ${ }^{13} \mathrm{C}-$ labelled lipids initially increased rapidly but then typically leveled off towards the end of the incubation (Fig. 3b, c). In addition significant amounts of the labelled substrate taken up by the microbes were used to produce polymeric carbohydrates (Table 1). These compounds were not subsequently broken down and converted into $\mathrm{CO}_{2}$; 
it is possible that their synthesis was due to the formation of new microbial cells or the production of storage compounds such as glycogen (Lundberg et al. 2001) or intermediate metabolites. These storage compounds might subsequently be used for respiration and growth if other nutrients become available allowing the continued synthesis of new microbial biomass (Lundberg et al. 2001). This suggestion is consistent with the gradual decline in the abundance of these polymeric carbohydrates towards the end of the incubation experiments. The potential for these storage compounds to be used in catabolic reactions producing $\mathrm{CO}_{2}$ at some later stage after they have been synthesized may introduce bias into over estimating CUE values and might be responsible for some of the differences in the calculated CUEs for different metabolic phases. The average CUE for the monomeric substrate (glucose) used in this study was around 0.7 (with a range from 0.5 to 0.9 ), being relatively high but still consistent with results obtained in previous studies on soil microorganisms utilizing glucose (CUE $=0.4$ to 0.8; Dijkstra et al. 2011a; Frey et al. 2013; Shields et al. 1973; Thiet et al. 2006). The production of $\mathrm{C} 1(\beta)$ polymeric carbohydrates ( i.e. cellobiose and cellulose) (Tables 1 and 2) also increased rapidly during the early stages of the incubations at all temperatures but later leveled off.

It is recognized that SOM to large extent is comprised of living and dead microbial biomass (Baldock et al. 1990; Miltner et al. 2012). Thus, correctly accounting the CUE of soil microbes are integral for understanding SOM dynamics, both during mineralization of e.g. plant material entering the soil system as well as recycling of microbial necromass. The results from this study allow us to draw three main conclusions regarding the CUE of soil microbes. The first relates to the quality of the carbon substrate since the CUE for a carbon polymer was found to be lower than that for the corresponding monomeric constituent. This finding emphasizes the importance of preferably assessing CUE of polymeric substrates, rather than exclusively focusing on monomers, in order to be relevant for natural conditions. The second is that the metabolic state at the time of sampling significantly affects the estimated CUE and should therefore be recorded when conducting studies of this sort. The third is that the CUE was dependent on the temperature for the monomeric substrate, with a reduction of CUE, when going from $9{ }^{\circ} \mathrm{C}$ to $19{ }^{\circ} \mathrm{C}$. For the polymeric substrate CUE was not dependent on temperature.
Acknowledgments The Swedish National Research Council, contract \# 2009-3060, 2012-2855 and the Centre for Environmental Research in Umeå, contract \#0522277 to MN financed this work. We thank Sören Holm, Bo Raneby and Staffan Åkerblom for help with statistical analyses and Anders Nordgren for technical support on the Respicond instrument.

Open Access This article is distributed under the terms of the Creative Commons Attribution 4.0 International License (http:// creativecommons.org/licenses/by/4.0/), which permits unrestricted use, distribution, and reproduction in any medium, provided you give appropriate credit to the original author(s) and the source, provide a link to the Creative Commons license, and indicate if changes were made.

\section{References}

Alexandersson H, Karlström C, Larsson-MacCann S (1991) Temperature and precipitation in Sweden 1961-90. Swedish Meteorological and Hydrological Institute (SMHI) Nr. 81/1990

Allison SD, Wallenstein MD, Bradford MA (2010) Soil-carbon response to warming dependent on microbial physiology. Nat Geosci 3:336-340

Ågren GI, Bosatta E (1987) Theoretical-analysis of the long-term dynamics of carbon and nitrogen in soils. Ecology 68:11811189

Ågren GI, Bosatta E, Magill AH (2001) Combining theory and experiment to understand effects of inorganic nitrogen on litter decomposition. Oecologia 128:94-98

Baldock JA, Oades JM, Vassallo AM, Wilson MA (1990) Significance of microbial activity in soils as demonstrated by solid-state ${ }^{13} \mathrm{C}$ NMR. Environ Sci Technol 24:527-530

Bergman I, Lundberg P, Nilsson M (1999) Microbial carbon mineralisation in an acid surface peat: effects of environmental factors in laboratory incubations. Soil Biol Biochem 31(13): 1867-1877

Bosatta E, Ågren G (1999) Soil organic matter quality interpreted thermodynamically. Soil Biol Biochem 31:1889-1891

del Giorgio PA, Cole JJ (1998) Bacterial growth efficiency in natural aquatic systems. Annu Rev Ecol Syst 29:503-541

Devevre OC, Horwath WR (2000) Decomposition of rice straw and microbial carbon use efficiency under different soil temperatures and moistures. Soil Biol Biochem 32:1773-1785

Dijkstra P, Dalder JJ, Selmants PC, Hart SC, Koch GW, Schwartz E, Hungate BA (2011a) Modeling soil metabolic processes using isotopologue pairs of positionspecific C-13-labelled glucose and pyruvate. Soil Biol Biochem 43:1848-1857

Dijkstra P, Thomas SC, Heinrich PL, Koch GW, Schwartz E, Hungate BA (2011b) Effect of temperature on metabolic activity of intact microbial communities: evidence for altered metabolic pathway activity but not for increased maintenance respiration and reduced carbon use efficiency. Soil Biol Biochem 43:2023-2031

Drotz SH, Sparrman T, Nilsson MB, Schleucher J, Öquist MG (2010a) Both catabolic and anabolic heterotrophic microbial 
activity proceed in frozen soils. Proc Natl Acad Sci U S A 107:21046-21051

Drotz SH, Sparrman T, Schleucher J, Nilsson MB, Öquist MG (2010b) Effects of soil organic matter composition on unfrozen water content and heterotrophic $\mathrm{CO} 2$ production of frozen soils. Geochim Cosmochim Acta 74: 2281-2290

Erhagen B, Öquist M, Sparrman T, Haei M, Ilstedt U, Hedenström M, Schleucher J, Nilsson MB (2013) Temperature response of litter and soil organic matter decomposition is determined by chemical composition of organic material. Glob Chang Biol 19(12):3858-3871

Fan TWM, Lane AN (2008) Structure-based profiling of metabolites and isotopomers by NMR. Prog Nucl Magn Reson Spectrosc 52:69-117

Farmer IS, Jones CW (1976) Effect of temperature on molar growth yield and maintenance requirement of Escherichiacoli-w during aerobic growth in continuous culture. Febs Letters 67:359-363

Frey SD, Lee JH, Melillo JM, Six J (2013) The temperature response of soil microbial efficiency and its feedback to climate. Nat Clim Chang 3:395-398

Frost PC, Benstead JP, Cross WF, Hillebrand H, Larson JH, Xenopoulos MA, Yoshida T (2006) Threshold elemental ratios of carbon and phosphorus in aquatic consumers. Ecol Lett 9:774-779

Gommers PJF, Vanschie BJ, Vandijken JP, Kuenen JG (1988) Biochemical limits microbial-growth yields-an analysis of mixed substrate utilization. Biotechnol Bioeng 32:86-94

Gottschalk G (1986) Bacterial metabolism, Second edition ed. Springer, New York, pp 359

Hall EK, Cotner JB (2007) Interactive effect of temperature and resources on carbon cycling by freshwater bacterioplankton communities. Aquat Microb Ecol 49:35-45

Ilstedt U, Nordgren A, Malmer A (2000) Optimum soil water for soil respiration before and after amendment with glucose in humid tropical acrisols and a boreal mor layer. Soil Biol Biochem 32:1591-1599

IPCC (2013) Annex I: atlas of global and regional climate projections. In: Stocker TF, Qin D, Plattner G-K, Tignor M, Allen SK, Boschung J, Nauels A, Xia Y, Bex V, Midgley PM (eds) Climate change 2013: the physical science basis. Contribution of working group I to the fifth assessment report of the intergovernmental panel on climate change. Cambridge University Press, Cambridge, United Kingdom and New York, NY, USA, pp. 1311-1394

Ladd JN, Oades JM, Amato M (1981) Microbial biomass formed from $14 \mathrm{C}, 15 \mathrm{~N}$-labelled plant material decomposing in soils in the field. Soil Biol Biochem 13:119-126

Lundberg P, Ekblad A, Nilsson M (2001) C-13 NMR spectroscopy studies of forest soil microbial activity: glucose uptake and fatty acid biosynthesis. Soil Biol Biochem 33:621-632

Mainzer SE, Hempfling WP (1976) Effects of growth temperature on yield and maintenance during glucoselimted continuous culture of escherichia-coli. J Bacteriol 126:251-256

Manzoni S, Porporato A (2009) Soil carbon and nitrogen mineralization: theory and models across scales. Soil Biol Biochem 41:1355-1379
Manzoni S, Taylor P, Richter A, Porporato A, Agren GI (2012) Environmental and stoichiometric controls on microbial carbon-use efficiency in soils. New Phytol 196:79-91

Martens R (1985) Limitations in the application of the fumigation technique for biomass estimations in amended soils. Soil Biol Biochem 17:57-63

Miltner A, Bombach P, Schmidt-Brücken B, Kästner M (2012) SOM genesis: microbial biomass as a significant source. Biogeochemistry 111:41-55

Nordgren A (1988) Apparatus for the continuous, long-term monitoring of soil respiration rate in large numbers of samples. Soil Biol Biochem 20:955-957

Nordgren A (1992) A method for determining Microbially available- $\mathrm{N}$ and available-P in an organic soil. Biol Fertil Soils 13:195-199

Nordgren A, Baath E, Soderstrom B (1988) Evaluation of soil respiration characteristics to assess heavy-metal effects on soil-microorganisms using glutamic-acid as a substrate. Soil Biol Biochem 20:949-954

Sattler M, Schleucher J, Griesinger C (1999) Heteronuclear multidimensional NMR experiments for the structure determination of proteins in solution employing pulsed field gradients. Prog Nucl Magn Reson Spectrosc 34:93-158

Schlesinger WH, Andrews JA (2000) Soil respiration and the global carbon cycle. Biogeochemistry 48:7-20

Shields JA, Paul EA, Lowe WE, Parkinson D (1973) Turnover of microbial tissue in soil under field conditions. Soil Biol Biochem 5:753-764

Sinsabaugh RL, Hill BH, Shah JJF (2009) Ecoenzymatic stoichiometry of microbial organic nutrient acquisition in soil and sediment. Nature 462:795-U117

Sinsabaugh RL, Manzoni S, Moorhead DL, Richter A (2013) Carbon use efficiency of microbial communities: stoichiometry, methodology and modelling. Ecol Lett 16:930-939

Soil Survey Staff (2003) Keys to soil taxonomy, 9 ed. United States Department of Agriculture, $332 \mathrm{pp}$

Spohn M (2014) Microbial respiration per unit microbial biomass depends on soil litter carbon-to-nitrogen ratio. Biogeosciences 11:15037-15051

Steinweg JM, Plante AF, Conant RT, Paul EA, Tanaka DL (2008) Patterns of substrate utilization during longterm incubations at different temperatures. Soil Biol Biochem 40:2722-2728

Sterner R, Elser J (2002) Ecological stoichiometry: the biology of elements from molecules to the biosphere. Princeton University Press, Princeton, NJ

Strandberg E, Sparrman T, Lindblom G (2001) Phase diagrams of systems with cationic alpha-helical membrane-spanning model peptides and dioleoylphosphatidylcholine. Adv Colloid Interf Sci 89:239-261

Tarnocai C, Canadell JG, Schuur EAG, Kuhry P, Mazhitova G, Zimov S (2009) Soil organic carbon pools in the northern circumpolar permafrost region. Glob Biogeochem Cycles 23(2). 10.1029/2008GB003327

Thiet RK, Frey SD, Six J (2006) Do growth yield efficiencies differ between soil microbial communities differing in fungal: bacterial ratios? Reality check and methodological issues. Soil Biol Biochem 38:837-844

van Hees PAW, Jones DL, Finlay R, Godbold DL, Lundstomd US (2005) The carbon we do not see - the impact of low 
molecular weight compounds on carbon dynamics and respiration in forest soils: a review. Soil Biol Biochem 37:1-13

Wetterstedt JAM, Ågren GI (2011) Quality or decomposer efficiency - which is most important in the temperature response of litter decomposition? A modelling study using the GLUE methodology. Biogeosciences 8:477-487
Winzler RJ, Baumberger PJ (1938) The degradation of energy in the metabolism of yeast cells. J Cell Comp Physiol 12:183211

Wolf DC, Dao TH, Scott HD, Lavy TL (1989) Influence of sterilization methods on selected soil microbiological, physical, and chemical properties. J Environ Qual 18(1):39 